thebmj

\title{
Letters
}

\section{Social exclusion must be considered in global terms}

BMJ 2001; 323 doi: http://dx.doi.org/10.1136/bmj.323.7325.1370/a (Published 08 December 2001) Cite this as: BMJ 2001;323:1370

\author{
J Jaime Miranda, Paul Farmer (jjmiranda@terra.com.pe) \\ EDHUCASalud, Civil Association for Health and Human Rights Education, Apartado Postal 9, Ayacucho, Peru \\ Program Infectious Diseases and Social Change, Harvard Medical School, Partners in Health, Boston, MA 02115, USA
}

EDITOR-The BMJ announced that the issue of 28 July would be dedicated to social exclusion. Given the journal's global readership, this generated many expectations: the underlying causes of patients' ills are not often the subject of commentary in the medical literature. The papers in the issue presented some of the British experience and one study from outside the United Kingdom.1

The BMJ has a tradition of attending to neglected medical topics, including poverty and access to drugs for HIV infection and AIDS. It also gives free access on the internet, thereby ending another sort of exclusion (lack of access to medical information in the settings in which burdens of disease are greatest). Beyond the borders of wealthy industrialised countries a substantial majority of all people are excluded from ready access to modern medical care. If the BMJ wants to continue in this internationalising vein (the title of the Editor's choice for the issue of 11 August was "Aspiring to be global"2) the analysis of international health matters should be deeper still, even if this requires more special theme issues.

One way of lessening exclusion is to hear the voices of the millions who are excluded not only from access to care but from access to a forum in which their exclusion is acknowledged. Are those on the receiving end of these lamentable conditions included in the definition of social exclusion or are they, in fact, excluded from the visibly excluded? Does one have to move to an industrialised country to have one's plight acknowledged? What are the boundaries of "our society" as used in the definition of social exclusion?

Exclusion is a concept that is supplanting older terms, from "oppressed" to "underclass." But it has not always been used in a sociologically or historically honest manner. Analysis of social exclusion in this global era will necessarily be transnational-otherwise, the growing outcome gap between the haves and have nots will be seen as a strictly national problem. Doctors know that the diseases we treat, or attempt to prevent, do not recognise such boundaries.

Linking analysis of exclusion to the conviction that access to health care should be a fundamental human right is the most sound means of moving towards inclusion. We would encourage editors to take a critical look at even the concept of social exclusion, which often becomes code for exclusions within 
an affluent society.

\section{References}

1.Editor's choice.Social exclusion: old problem, new name.BMJ2001;323 (7306). (28 July.)

2.Editor's choice.Aspiring to be global.BMJ2001;323 (7308). (11 August.) 